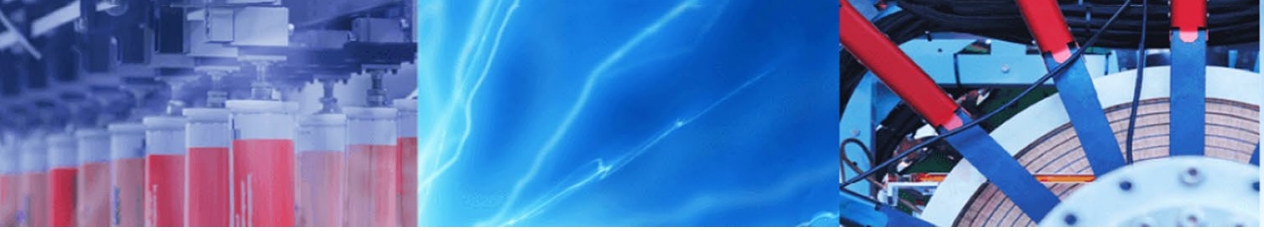

Research Article

\title{
Design methods for spiral stirrups confined concrete columns by evaluating the lateral performance of transverse reinforcements
}

\author{
Dechao Qu ${ }^{1} \cdot$ Wei Chang ${ }^{2}$
}

Received: 5 September 2019 / Accepted: 22 November 2019 / Published online: 28 November 2019

(c) Springer Nature Switzerland AG 2019

\begin{abstract}
Transverse reinforcements may not yield at the peak stress of confined concrete when the tensile strength and volumetric ratio of lateral steel do not be coordinate with concrete strength. The compressive strength and ductility of confined concrete are closely related to the lateral strain of transverse reinforcement at peak stress. However, determining the lateral strain of transverse reinforcements at peak stress is difficult due to many parameters should be considered. In this paper, a regression analysis model and an artificial neural network (ANN) model were developed to predict the lateral strain in transverse reinforcements and an ANN model was established to determine the volumetric ratio ranges of transverse reinforcements which transverse reinforcements yield at the peak stress of confined concrete. To reach the purpose, 111-group data sets assembled from previous studies were applied to test the effects of influential parameters on the lateral strain and judge whether transverse reinforcements yield at the peak stress of confined concrete. The aspect ratio of specimens, the tensile yield strength and volumetric ratio of transverse reinforcements, the compressive strength of unconfined concrete, as well as longitudinal reinforcements ratio were considered. For lateral strain prediction models, the regression analysis equation was proposed based on theoretical analysis, while the ANN model was determined by collected data; for appropriate volumetric ratio ranges determination model, the outputs of ANN model were based on the classification method to judge the lateral steel yields. The results showed that the prediction models of lateral strain had high efficiency for predicting lateral strain. Besides, the accuracy and the prediction ability of the ANN model was higher than regression analysis model. Furthermore, the appropriate volumetric ratio ranges of transverse reinforcements in different confined concrete were calculated by proposed ANN model. Finally, the recommended lateral strain prediction models and volumetric ratio of transverse reinforcements determination model can be utilized to instruct the design of confined concrete.
\end{abstract}

Keywords Lateral strain · Transverse reinforcements, confined concrete columns · Prediction model · Appropriate volumetric ratio ranges

\section{Introduction}

In recent years, high-strength concrete over $100 \mathrm{MPa}$ has been applied to engineer construction. The advantages of the application of high-strength concrete in engineering were evident in construction design, economy, and environment, but high-strength concrete had obvious brittle characteristic [1, 2]. Applying spiral stirrups to confine concrete was an efficient way to improve the ductility of concrete $[3,4]$. However, in confined concrete, if low-strength steel confined high-strength concrete, the steel could not provide effective confining pressure for concrete and steel might rupture at the peak stress of confined concrete; on the contrary, if high-strength

Wei Chang, changweihit@163.com | 'School of Transportation Science and Engineering, Harbin Institute of Technology, Harbin 150090, China. ${ }^{2}$ School of Civil Engineering, Harbin Institute of Technology, 202 Haihe Road, Nangang District, Harbin 150090, China. 
steel confined normal-strength concrete, steel might not yield at the peak stress of confined concrete causing the strength of steel could not be adequately developed. The strength and number of stirrups should be coordinate with the compressive strength of concrete to ensure that steel yield at the peak stress of confined concrete. The strain of stirrups at the peak stress of confined concrete was an important indicator to evaluate the compatibility between stirrups and concrete. Unfortunately, predicting the lateral strain was a huge challenge due to the complicated mechanism between stirrups and concrete [5].

In past decades, researchers have established the models for evaluating the performance of spiral stirrups confined concrete. The studies was divided into two groups: the one was the predictions of the peak strain, peak stress, and stress-strain curves of confined concrete, the other was the determination of the appropriate ranges of the volumetric ratio of stirrups and the lateral performance evaluation of stirrups. The former group mainly focused on the compressive behavior of confined concrete and was used to instruct the design of confined concrete. Richart et al. [6, 7] proposed the calculation equations of peak stress of confined concrete which was an application of normal-strength concrete; Mander et al. [5] proposed the confined coefficient to evaluate the effects of transverse reinforcements on the peak strain and peak stress of confined concrete based on the experimental results [8-10]. The subsequent researchers focused on modifying the confined coefficient by experimental and theoretical analysis to adapt the normal- and high-strength concrete. The latter one focused on adjusting the volumetric ratio of transverse reinforcements to ensure that transverse reinforcements yield at the peak stress of confined concrete. The calculation equations of minimum volumetric ratio of transverse reinforcements in confined concrete were determined in $\mathrm{ACl} 318$ [11]; Zheng et al. [12] proposed a model for predicting the volumetric ratio of transverse reinforcements in spiral stirrups confined concrete by three-dimension regression analysis by considering the tensile yield strain of stirrups and concrete strength to ensure that transverse reinforcements yield, the model could be used to guide the design of confined concrete less than $60 \mathrm{MPa}$; Dong et al. $[13,14]$ proposed a constitute model for predicting the lateral strain of both passive and active confined concrete, which was adapted for the concrete strength ranged from $25 \mathrm{MPa}$ to $120 \mathrm{MPa}$; Kim et al. [15] modified the minimum volumetric ratio equations of transverse reinforcements based on the $\mathrm{ACl} 318$ to improve the ductility of reinforced concrete columns and to recover their stress; Alacali et al. [16] predicted the lateral confinement coefficient in reinforced concrete columns by neural network models to estimate the confinement degree of stirrups. The recommended model can be utilized to predict the concrete within 19.6-56.4 MPa. From previous studies, the existing models were applicable for the design of spiral stirrups confined normal-strength concrete, as for high-strength concrete, the existing models should modify the parameters in models. Besides, in existing models, the lateral strain of transverse reinforcements may not yield at peak stress, the strength of transverse reinforcements could not be fully developed, meanwhile, the proposed models assumed that spiral stirrups totally yielded when confined concrete columns reached peak stress in low volumetric ratio of lateral steel, but proposed models might not applicable for high-strength concrete for its brittle failure. Moreover, high-strength steel might not yield in normal-strength concrete, determining the appropriate ranges of volumetric ratio of transverse reinforcements for different strength concrete was an important procedure for the design of confined concrete. Furthermore, when new experiment data exceeded a specific range of concrete strength was introduced to the existing models, the models should be re-evaluated. Thus, it was necessary to establish the models for predicting the lateral strain of stirrups and determining volumetric ratio of stirrups in appropriate ranges to ensure that lateral steel yield at peak stress.

The objective of this paper was to propose two models for predicting the lateral strain of stirrups and determining the appropriate volumetric ratio ranges of transverse reinforcements. To reach the purpose, a reliable database containing 111-group datasets from previous experimental studies was assembled and the appropriate volumetric ratio ranges of transverse reinforcements were determined by the proposed model.

\section{Theoretical analysis and model introduction}

\subsection{Theoretical analysis}

In spiral stirrups concrete columns, the lateral stress of transverse reinforcements provided by confined concrete alongside the edge of confined concrete was affected by the tensile strength and volumetric ratio of transverse reinforcements, as well as concrete strength (In Fig. 1).

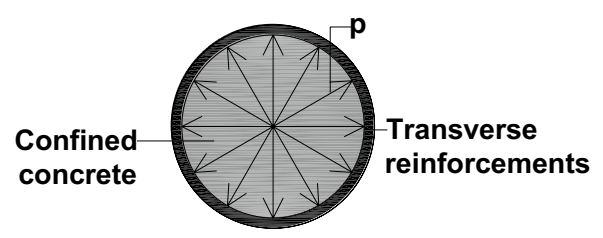

Fig. 1 Distribution of lateral stress in transverse reinforcements 
Based on experimental researches, many lateral stress calculation equations evaluated the effects of transverse reinforcements on the compressive behaviors of confined concrete were proposed $[5,8-10]$ and the lateral strain was a crucial parameter to estimate the compressive behavior of confined concrete. In Fig. 1, when concrete columns was under compression, concrete expanded in lateral direction and core concrete pushed spiral stirrups, the lateral strain in transverse reinforcements occurred.

In Fig. 2, the initial diameter of confined concrete was $D$. When compression load was $F$, the diameter of confined concrete $D$ changed to $D+\Delta D$, meanwhile, the diameter of spiral stirrups changed with the diameter of confined concrete, so that the lateral strain can be expressed in Eq. (1).

$\varepsilon_{l}=\Delta D / D$

$\Delta D$ was related to Poisson's ratio $v$ and $v$ was related to the compressive strength of concrete. Equation (1) can be transformed as follows:

$\varepsilon_{l}=\Delta D / D=v \Delta / / D=v L \Delta / / L D=v \varepsilon_{c c} L / D=\alpha \varepsilon_{c c} v$

where $\Delta /$ was the vertical deformation of concrete columns; $\varepsilon_{c c}$ was the peak strain of confined concrete related to the compressive strength of concrete, as well as the volumetric ratio and tensile strength of transverse reinforcements. Many studies have researched on predicting the peak strain of confined concrete, however, they did not consider the influence of aspect ratio of specimens. Therefore, in this paper, the lateral strain of transverse reinforcement model was established based on the Eq. (3).

$\varepsilon_{l}=\alpha \varepsilon_{c c} v=\alpha f\left(f_{c^{\prime}}^{\prime} \rho_{s v}, f_{s v}\right)$

\subsection{Model introduction}

To predict the lateral strain of stirrups and determine the appropriate ranges of the volumetric ratio of confined concrete, a regression model and an ANN model were

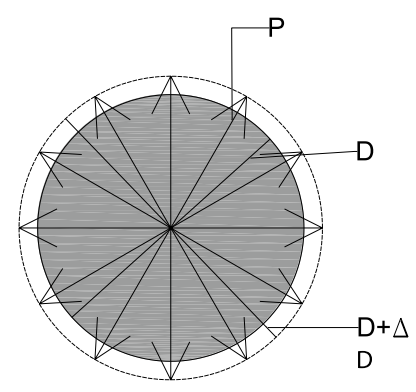

Fig. 2 Lateral deformation in confined concrete established based on Eq. (3). The introductions of Those two analytical methods were as follows:

\subsubsection{Regression analysis}

Regression analysis was always applied to establish the calculation models to evaluate the relationship among variables [17]. Regression analysis mainly focused on analyzing the relationships between a dependent variable and one or more independent variables, which meant that the dependent variable changed with a specific independent variable varying and other independent variables held fixed $[18,19]$. Regression analysis was widely used for predicting and evaluating the relationships among the independent variables and dependent variable. The techniques for regression analysis had two types: the one was parametric methods, which included linear regression and ordinary least squares regression, the regression function of this type was defined in terms of a finite number of unknown parameters that were estimated from the data; the other one was nonparametric regression that allowed the regression function to lie in a specified set of functions, which may be infinite-dimensional [17]. The regression models involved the following parameters and variables:

- The unknown parameters, denoted as $\beta$ represents a scalar or a vector;

- The independent variables, $X$;

- The dependent variable, $Y$.

A regression model related $Y$ to a function of $X$ and $\beta$ :

$Y \approx f(X, \beta)$

The procedures for regression analyzing were as following:

- Determine variables. Determine the independent variable and dependent variables from experimental data, and select the primary dependent variables for independent variable;

- Establish a prediction model. Establish a regression analysis prediction model based on the theoretical analysis;

- Analyze correlation. The correlation analysis between the independent variable and dependent variables is determined by the correlation coefficient to judge the degree of correlation relationship between independent variable and dependent variables;

- Calculate prediction errors. To test the reliable and the predictable of the regression analysis prediction model, the errors between predicted values and experimental values should be calculated. 
The method of regression analysis for estimating the relationships among variables was the least square regression analysis. The regression analysis prediction models included linear regression and nonlinear regression [20].

\subsubsection{Artificial neural network model}

Artificial neural networks (ANN) is a computer model that simulates the structure and working principle of the biological nervous systems. Similar to the biological nervous system, the ANN model consisted of a great number of highly interconnected neurons, and acquires intelligent characteristics after training. The topological structure of typical ANN was multi-layer feed forward perception network, in which the numerous neurons are distributed into three or more layers, including an input layer, one or more hidden layers, and an output layer, as shown in Fig. 3. In this network, all neurons in each layer are connected to next layer, and no connection among neurons at the same layer. The conversion between input and output layer is through adjusting the weights and thresholds among layers. Eventually, if the problem can be learned, a set of weights will be stable and a good result will be obtained.

The Back-Propagation (BP) neural network is one of the ANN solving the nonlinear problems. Generally, the BP neural network has three layers: the input layer, hidden layers, and the output layer (In Fig. 4). The neurons are distributed into three layers, all neurons are linked with each other in different layers, while there are no links among neurons in the same layer. The training processes of a BP network has two stages: the forward stage and the backward stage. The forward stage calculates the network outputs through the given initial connection weights and input data. In the process, the input data is passed from the input layer to the hidden layer. Then the neurons in the hidden layer calculate a weighted sum of the input data, processes the sum by using an activation function, and finally pass the activation results to the output layer; in the backward stage, the errors between the calculated

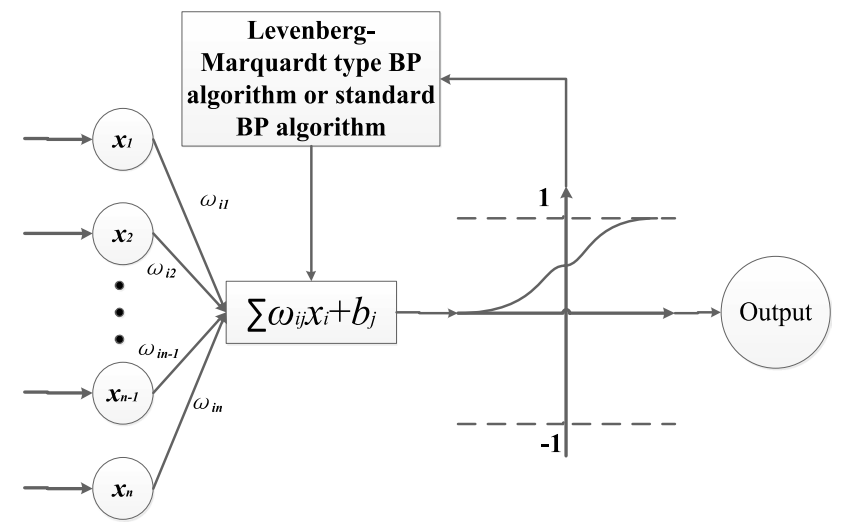

Fig. 4 System of typical BP model. A typical BP model has input, sum function, log-sigmoid activation function, and output

outputs and the experimental results are calculated, and the errors are passed back to the network to modify the connection weights and bias. This process is repeated until the errors reach an acceptable level [21-23].

In this study, the training method of the ANN model used the LM (Levenberg-Marquardt) algorithm, because the LM algorithm combined the advantages of the QuasiNewton algorithm and the Steepest Descent Backpropagation, which was suitable for solving non-linear least square problems [23].

\section{Experimental database and model establishment}

\subsection{Experimental test database}

A reliable database was established by assembling the experimental test data under axial compression [24-30]. In the database, the diameter, the spacing, the tensile strength, the yield stress, and the volumetric ratio of transverse reinforcements, as well as the compressive strength

Fig. 3 System of typical ANN model

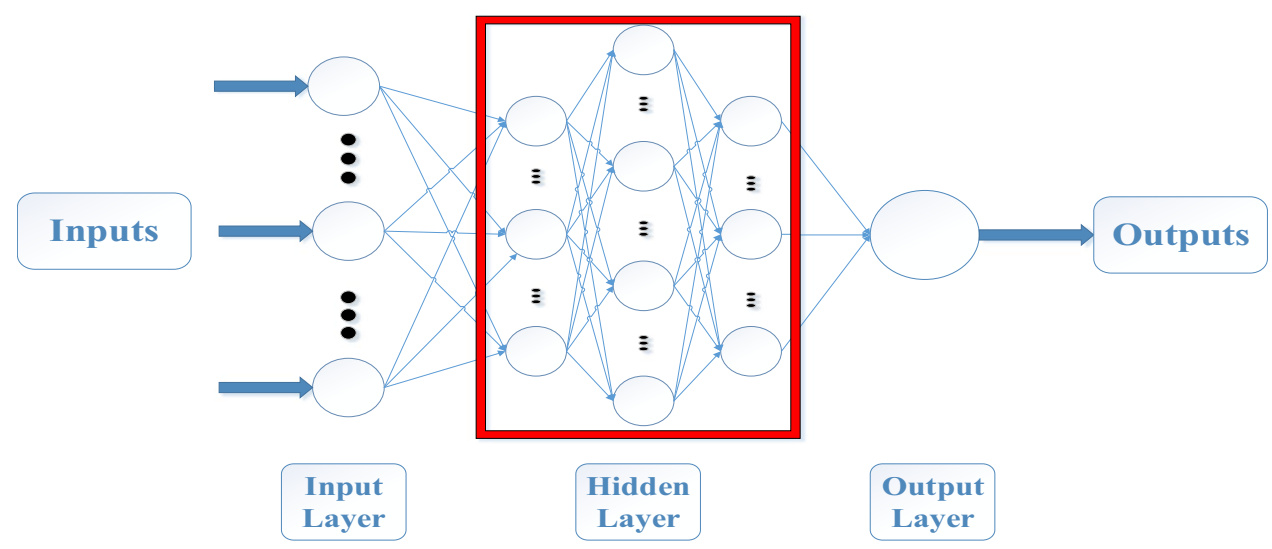


unconfined concrete were considered to establish the model for predicting the lateral strain of stirrups. Table 1 shows the collected experimental test data.

In the database, the diameter and height of specimens varied from $102 \times 203 \mathrm{~mm}$ to $440 \times 1500 \mathrm{~mm}$; the diameter, the spacing, the tensile strength, and the volumetric ratio of transverse reinforcements varied from 5.1 to $12 \mathrm{~mm}, 13$ to $135 \mathrm{~mm}, 307$ to $1318 \mathrm{MPa}, 0.082$ to $0.703 \%$, and 0.36 to $14.8 \%$, respectively; the compressive strength of unconfined concrete were $25.04-151 \mathrm{MPa}$; the lateral strain of stirrups in confined concrete varied from 0.027 to $1.488 \%$.

\subsection{Establishing models}

\subsubsection{Regression analysis prediction model}

To develop the regression prediction model, the aspect ratio of specimens, the volumetric ratio and strength of stirrups, the compressive strength of concrete, as well as longitudinal reinforcements ratio were considered. Based on the previous study [5], the form of calculation model for the lateral stress of stirrups is listed as following:

$f_{l}=k \rho_{s v} f_{s v}$

where $k$ was the coefficient related to the space and diameter of stirrups, as well as the ratio of longitudinal reinforcements.

Combining Eq. (3) with Eq. (5), the regression analysis model for predicting the lateral strain of stirrups is expressed in Eq. (6).

$\varepsilon_{l}=k \alpha^{a} f_{c}^{\prime} b f_{s v}^{c} \rho_{s v}^{d} \rho_{c}^{e}$

where $k, a, b, c, d$, e were regression coefficients.

By regression analysis, the regression analysis prediction model was obtained.

$\varepsilon_{l}=0.6163 \alpha^{-1.7752} f_{c}^{\prime-0.7031} f_{s V}^{0.5979} \rho_{s V}^{0.4926}\left(1-\rho_{c}\right)^{-13.0923}$

\subsubsection{ANN model}

Similarly, ANN model was adopted to predict the lateral strain of stirrups. Based on the collected data, the ANN model was trained and tested. Because there was no analytical model for calculating the number of hidden layer and the neural nodes of hidden layers in ANN model, the proposed ANN model should be trained many times for its prediction and accuracy. When ANN model had acceptable results, the weights and the thresholds were stable. In this paper, $80 \%$ (88 groups) of collected data sets were selected to train the ANN model while remaining data sets ( 23 groups) were tested the accuracy of the proposed model. The inputs parameters included the compressive strength of unconfined concrete, the tensile strength and the voluimetric ratio of transverse reinforcements, the aspect ratio of specimens, as well as longitudinal reinforcements ratios, while the output values was the lateral strain of transverse reinforcements. After a series of trials, an acceptable ANN model for predicting the lateral strain of stirrups in confined concrete was obtained and the indicators reach the satisfactory values. Table 2 lists the parameters of the proposed models.

There were three indicators for evaluating the prediction performance of the models: the root-mean-square error (RMSE), average absolute error, and the determine coefficient $\left(R^{2}\right)$. The calculation equations of indicators were described as following.

RMSE $=\sqrt{\frac{1}{N}\left(\sum_{i=1}^{N}\left(\frac{o_{i}-x_{i}}{x_{i}}\right)^{2}\right)}$

$\mathrm{AAE}=\frac{1}{\mathrm{~N}} \sum_{i=1}^{N} \frac{\left|o_{i}-x_{i}\right|}{x_{i}}$

$R^{2}=1-\frac{\sum_{i=1}^{N}\left(o_{i}-x_{i}\right)^{2}}{\sum_{i=1}^{N} x_{i}^{2}}$

where $N$ was the total number of data sets; $o_{i}$ and $x_{i}$ were the outputs of the proposed models and the experimental test results, respectively.

\section{Results and discussion}

To evaluate the predictable and accuracy of proposed models, the predicted values from recommended models should compare with collected data sets. Figure 5 and Table 3 show the comparison between predicted results from the proposed models and experimental results and the indicators for evaluating the prediction performance of proposed models, respectively. As for the proposed regression analysis prediction model and the ANN model, the almost predicted values from the regression analysis model and ANN model were both within -10 to $+10 \%$. Meanwhile, the RMSE, AAE and $R^{2}$ for regression analysis model and ANN model are 1.1590 and $0.8542,0.6689$ and 0.5077 , and 0.7840 and 0.9206 , respectively. It indicated that those two proposed models had high accuracy for predicting the lateral strain of stirrups in confined concrete. Besides, the ANN model was more suitable for predicting the lateral strain than regression analysis model for its high predictable and high accuracy. 
Table 1 The details of collected data sets for establishing model

\begin{tabular}{|c|c|c|c|c|c|c|c|c|c|c|c|}
\hline Literature & $D(\mathrm{~mm})$ & $H(\mathrm{~mm})$ & $d(\mathrm{~mm})$ & $S(\mathrm{~mm})$ & $f_{s v}(\mathrm{Mpa})$ & $\rho_{s v}(\%)$ & $\varepsilon_{s v}(\%)$ & $f_{c}^{\prime} / \mathrm{MPa}$ & $\varepsilon_{l}(\%)$ & $\begin{array}{l}\text { Lateral strain } \\
\text { ANN model }\end{array}$ & $\begin{array}{l}\text { Appropriate volu- } \\
\text { metric ratio ANN } \\
\text { model }\end{array}$ \\
\hline \multirow[t]{15}{*}{ Mander [24] } & 440 & 1500 & 12 & 52.00 & 310 & 1.99 & 0.15 & 24 & 0.483 & Testing & Training \\
\hline & 440 & 1500 & 12 & 52.00 & 340 & 1.99 & 0.17 & 30 & 0.261 & Training & Training \\
\hline & 440 & 1500 & 12 & 52.00 & 340 & 1.99 & 0.17 & 32 & 0.183 & Training & Training \\
\hline & 440 & 1500 & 12 & 41.00 & 340 & 2.52 & 0.17 & 29 & 0.681 & Training & Testing \\
\hline & 440 & 1500 & 12 & 69.00 & 340 & 1.50 & 0.17 & 29 & 0.185 & Training & Training \\
\hline & 440 & 1500 & 12 & 103.00 & 340 & 1.00 & 0.17 & 29 & 0.291 & Training & Testing \\
\hline & 440 & 1500 & 10 & 119.00 & 320 & 0.60 & 0.16 & 29 & 0.182 & Training & Training \\
\hline & 440 & 1500 & 10 & 36.00 & 320 & 1.98 & 0.16 & 29 & 0.351 & Training & Training \\
\hline & 440 & 1500 & 16 & 93.00 & 307 & 1.97 & 0.15 & 29 & 0.332 & Training & Training \\
\hline & 440 & 1500 & 12 & 52.00 & 340 & 1.99 & 0.17 & 32 & 0.443 & Training & Training \\
\hline & 440 & 1500 & 12 & 52.00 & 340 & 1.99 & 0.17 & 30 & 0.203 & Training & Testing \\
\hline & 440 & 1500 & 12 & 52.00 & 340 & 1.99 & 0.17 & 32 & 0.182 & Training & Training \\
\hline & 440 & 1500 & 12 & 52.00 & 340 & 1.99 & 0.17 & 30 & 0.173 & Training & Training \\
\hline & 440 & 1500 & 12 & 52.00 & 340 & 1.99 & 0.17 & 30 & 0.226 & Testing & Training \\
\hline & 440 & 1500 & 12 & 52.00 & 340 & 1.99 & 0.17 & 32 & 0.388 & Testing & Testing \\
\hline \multirow[t]{7}{*}{ Antonius [25] } & 110 & 550 & 6.25 & 35.00 & 488 & 4.38 & 0.1584 & 44.55 & 0.185 & Training & Training \\
\hline & 110 & 550 & 6.25 & 35.00 & 488 & 4.38 & 0.1584 & 54.98 & 0.145 & Testing & Training \\
\hline & 110 & 550 & 5.5 & 35.00 & 315 & 3.19 & 0.082 & 54.98 & 0.131 & Training & Testing \\
\hline & 110 & 550 & 5.5 & 55.00 & 315 & 2.03 & 0.082 & 54.98 & 0.0936 & Training & Training \\
\hline & 110 & 550 & 6.25 & 35.00 & 488 & 4.38 & 0.1584 & 62.5 & 0.0228 & Testing & Training \\
\hline & 110 & 550 & 6.25 & 35.00 & 587 & 4.38 & 0.1737 & 62.5 & 0.11 & Training & Training \\
\hline & 110 & 550 & 6.25 & 55.00 & 587 & 2.79 & 0.1737 & 62.5 & 0.285 & Training & Testing \\
\hline \multirow[t]{24}{*}{ Assa [26] } & 145 & 300 & 6.25 & 27.75 & 1296 & 3.05 & 0.67 & 25.04 & 1.37 & Training & Training \\
\hline & 145 & 300 & 6.25 & 44.17 & 1296 & 1.92 & 0.67 & 25.04 & 0.92 & Training & Training \\
\hline & 145 & 300 & 6.25 & 20.40 & 1296 & 4.15 & 0.67 & 34.13 & 1.48 & Training & Testing \\
\hline & 145 & 300 & 6.25 & 27.80 & 1296 & 3.04 & 0.67 & 34.13 & 1.13 & Testing & Training \\
\hline & 145 & 300 & 6.25 & 46.90 & 1296 & 1.80 & 0.67 & 34.13 & 0.61 & Training & Training \\
\hline & 145 & 300 & 6.25 & 50.00 & 909 & 1.69 & 0.44 & 34.13 & 0.61 & Training & Training \\
\hline & 145 & 300 & 6.25 & 75.00 & 909 & 1.13 & 0.44 & 34.13 & 0.28 & Training & Training \\
\hline & 145 & 300 & 6.25 & 27.75 & 1296 & 3.05 & 0.67 & 41.38 & 1.02 & Testing & Training \\
\hline & 145 & 300 & 6.25 & 44.17 & 1296 & 1.92 & 0.67 & 41.38 & 0.61 & Training & Testing \\
\hline & 145 & 300 & 6.25 & 27.75 & 1296 & 3.05 & 0.67 & 49.75 & 0.99 & Training & Training \\
\hline & 145 & 300 & 6.25 & 44.17 & 1296 & 1.92 & 0.67 & 49.75 & 0.56 & Training & Testing \\
\hline & 145 & 300 & 6.25 & 28.00 & 1296 & 3.02 & 0.67 & 64.40 & 0.77 & Training & Training \\
\hline & 145 & 300 & 6.25 & 27.75 & 1296 & 3.05 & 0.67 & 64.40 & 0.63 & Training & Training \\
\hline & 145 & 300 & 6.25 & 44.17 & 1296 & 1.92 & 0.67 & 64.40 & 0.53 & Testing & Training \\
\hline & 145 & 300 & 6.25 & 28.00 & 1296 & 3.02 & 0.67 & 70.10 & 0.64 & Training & Training \\
\hline & 145 & 300 & 6.25 & 44.17 & 1296 & 1.92 & 0.67 & 70.10 & 0.27 & Training & Training \\
\hline & 145 & 300 & 6.25 & 20.40 & 1296 & 4.15 & 0.67 & 83.03 & 0.93 & Training & Testing \\
\hline & 145 & 300 & 6.25 & 28.12 & 1296 & 3.01 & 0.67 & 83.03 & 0.55 & Training & Training \\
\hline & 145 & 300 & 6.25 & 46.60 & 1296 & 1.82 & 0.67 & 83.03 & 0.29 & Testing & Training \\
\hline & 145 & 300 & 6.25 & 50.00 & 909 & 1.69 & 0.44 & 83.03 & 0.24 & Training & Testing \\
\hline & 145 & 300 & 6.25 & 75.00 & 909 & 1.13 & 0.44 & 83.03 & 0.21 & Training & Training \\
\hline & 145 & 300 & 6.25 & 25.00 & 1296 & 3.38 & 0.67 & 75.04 & 0.53 & Training & Training \\
\hline & 145 & 300 & 6.25 & 38.00 & 1296 & 2.23 & 0.67 & 75.04 & 0.23 & Training & Training \\
\hline & 145 & 300 & 6.25 & 25.00 & 1296 & 3.38 & 0.67 & 74.49 & 0.48 & Testing & Testing \\
\hline \multirow[t]{2}{*}{ Li [27] } & 210 & 720 & 6 & 20.00 & 445 & 2.69 & 0.255 & 63 & 0.429 & Training & Training \\
\hline & 210 & 720 & 6 & 35.00 & 445 & 1.54 & 0.255 & 63 & 0.45 & Training & Training \\
\hline
\end{tabular}


Table 1 (continued)

\begin{tabular}{|c|c|c|c|c|c|c|c|c|c|c|c|}
\hline Literature & $D(\mathrm{~mm})$ & $H(\mathrm{~mm})$ & $d(\mathrm{~mm})$ & $S(\mathrm{~mm})$ & $f_{s v}(\mathrm{Mpa})$ & $\rho_{s V}(\%)$ & $\varepsilon_{s v}(\%)$ & $f_{c}^{\prime} / \mathrm{MPa}$ & $\varepsilon_{l}(\%)$ & $\begin{array}{l}\text { Lateral strain } \\
\text { ANN model }\end{array}$ & $\begin{array}{l}\text { Appropriate volu- } \\
\text { metric ratio ANN } \\
\text { model }\end{array}$ \\
\hline & 210 & 720 & 6 & 50.00 & 445 & 1.08 & 0.255 & 63 & 0.154 & Training & Training \\
\hline & 210 & 720 & 6 & 65.00 & 445 & 0.83 & 0.255 & 63 & 0.341 & Testing & Training \\
\hline & 210 & 720 & 6 & 20.00 & 445 & 2.69 & 0.255 & 72.3 & 0.466 & Training & Testing \\
\hline & 210 & 720 & 6 & 35.00 & 445 & 1.54 & 0.255 & 72.3 & 0.369 & Training & Training \\
\hline & 210 & 720 & 6 & 50.00 & 445 & 1.08 & 0.255 & 72.3 & 0.0756 & Training & Training \\
\hline & 210 & 720 & 6 & 65.00 & 445 & 0.83 & 0.255 & 72.3 & 0.0897 & Training & Training \\
\hline & 210 & 720 & 6.4 & 20.00 & 1318 & 2.94 & 0.634 & 52 & 1.46 & Training & Testing \\
\hline & 210 & 720 & 6.4 & 35.00 & 1318 & 1.67 & 0.634 & 52 & 1.15 & Testing & Training \\
\hline & 210 & 720 & 6.4 & 50.00 & 1318 & 1.17 & 0.634 & 52 & 1.49 & Training & Training \\
\hline & 210 & 720 & 6.4 & 20.00 & 1318 & 2.94 & 0.634 & 82.5 & 1.13 & Training & Testing \\
\hline & 210 & 720 & 6.4 & 35.00 & 1318 & 1.67 & 0.634 & 82.5 & 1.11 & Testing & Training \\
\hline & 210 & 720 & 6.4 & 50.00 & 1318 & 1.17 & 0.634 & 82.5 & 1.09 & Training & Training \\
\hline & 210 & 720 & 6.4 & 35.00 & 1318 & 1.68 & 0.634 & 35.2 & 0.87 & Training & Training \\
\hline & 210 & 720 & 6.4 & 53.00 & 1318 & 1.10 & 0.634 & 35.2 & 0.71 & Testing & Testing \\
\hline & 210 & 720 & 6.4 & 70.00 & 1318 & 0.84 & 0.634 & 35.2 & 0.48 & Training & Training \\
\hline \multirow[t]{32}{*}{ Montgomery [28] } & 254 & 1016 & 11.3 & 41.00 & 522 & 1.17 & 0.24 & 69.7 & 0.193 & Training & Training \\
\hline & 254 & 1016 & 11.3 & 53.00 & 522 & 3.62 & 0.24 & 69.7 & 0.101 & Training & Testing \\
\hline & 254 & 1016 & 11.3 & 79.00 & 522 & 2.43 & 0.24 & 69.7 & 0.244 & Testing & Training \\
\hline & 254 & 1016 & 11.3 & 109.00 & 522 & 1.76 & 0.24 & 69.7 & 0.22 & Training & Training \\
\hline & 254 & 1016 & 8 & 41.00 & 666 & 2.23 & 0.653 & 69.7 & 0.166 & Training & Training \\
\hline & 254 & 1016 & 8 & 53.00 & 666 & 1.73 & 0.653 & 69.7 & 0.114 & Training & Training \\
\hline & 254 & 1016 & 8 & 79.00 & 666 & 1.16 & 0.653 & 69.7 & 0.0467 & Testing & Testing \\
\hline & 254 & 1016 & 8 & 109.00 & 666 & 0.84 & 0.653 & 69.7 & 0.0656 & Training & Training \\
\hline & 254 & 1016 & 5.7 & 41.00 & 583 & 1.17 & 0.488 & 69.7 & 0.132 & Training & Training \\
\hline & 254 & 1016 & 5.7 & 53.00 & 583 & 0.91 & 0.488 & 69.7 & 0.25 & Testing & Training \\
\hline & 203 & 813 & 11.3 & 64.00 & 522 & 3.77 & 0.24 & 69.7 & 0.515 & Training & Testing \\
\hline & 203 & 813 & 9.5 & 43.00 & 508 & 3.96 & 0.275 & 69.7 & 0.627 & Training & Training \\
\hline & 203 & 813 & 9.5 & 64.00 & 508 & 2.66 & 0.275 & 69.7 & 0.206 & Training & Training \\
\hline & 203 & 813 & 9.5 & 86.00 & 508 & 1.98 & 0.275 & 69.7 & 0.225 & Training & Training \\
\hline & 203 & 813 & 8 & 64.00 & 666 & 1.79 & 0.491 & 69.7 & 0.113 & Training & Testing \\
\hline & 203 & 813 & 6.4 & 43.00 & 646 & 1.76 & 0.524 & 69.7 & 0.0306 & Testing & Training \\
\hline & 203 & 813 & 6.4 & 64.00 & 646 & 1.18 & 0.524 & 69.7 & 0.167 & Training & Training \\
\hline & 203 & 813 & 6.4 & 86.00 & 646 & 0.88 & 0.524 & 69.7 & 0.0411 & Training & Training \\
\hline & 203 & 813 & 4.8 & 43.00 & 692 & 0.96 & 0.653 & 69.7 & 0.359 & Training & Training \\
\hline & 203 & 813 & 11.3 & 43.00 & 522 & 5.61 & 0.24 & 89.8 & 0.856 & Training & Testing \\
\hline & 203 & 813 & 11.3 & 64.00 & 522 & 3.77 & 0.24 & 89.8 & 0.216 & Testing & Training \\
\hline & 203 & 813 & 11.3 & 86.00 & 522 & 2.81 & 0.24 & 89.8 & 0.148 & Training & Training \\
\hline & 203 & 813 & 9.5 & 43.00 & 508 & 3.96 & 0.275 & 89.8 & 0.25 & Training & Training \\
\hline & 203 & 813 & 9.5 & 64.00 & 508 & 2.66 & 0.275 & 89.8 & 0.167 & Training & Testing \\
\hline & 203 & 813 & 9.5 & 86.00 & 508 & 1.98 & 0.275 & 89.8 & 0.204 & Testing & Training \\
\hline & 203 & 813 & 8 & 43.00 & 666 & 2.67 & 0.491 & 89.8 & 0.208 & Training & Training \\
\hline & 203 & 813 & 8 & 64.00 & 666 & 1.79 & 0.491 & 89.8 & 0.142 & Training & Testing \\
\hline & 203 & 813 & 8 & 86.00 & 666 & 1.33 & 0.491 & 89.8 & 0.422 & Testing & Training \\
\hline & 203 & 813 & 6.4 & 43.00 & 646 & 1.76 & 0.524 & 89.8 & 0.0957 & Training & Training \\
\hline & 203 & 813 & 6.4 & 64.00 & 646 & 1.18 & 0.2524 & 89.8 & 0.0471 & Training & Training \\
\hline & 203 & 813 & 6.4 & 86.00 & 646 & 0.88 & 0.524 & 89.8 & 0.307 & Training & Training \\
\hline & 203 & 813 & 4.8 & 43.00 & 692 & 1.74 & 0.653 & 89.8 & 0.0321 & Testing & Training \\
\hline Razvi [29] & 240 & 1500 & 6.3 & 70.00 & 660 & 0.8 & 0.529 & 60 & 0.0625 & Training & Testing \\
\hline
\end{tabular}


Table 1 (continued)

\begin{tabular}{|c|c|c|c|c|c|c|c|c|c|c|c|}
\hline Literature & $D(\mathrm{~mm})$ & $H(\mathrm{~mm})$ & $d(\mathrm{~mm})$ & $S(\mathrm{~mm})$ & $f_{s v}(\mathrm{Mpa})$ & $\rho_{s V}(\%)$ & $\varepsilon_{s v}(\%)$ & $f_{c}^{\prime} / \mathrm{MPa}$ & $\varepsilon_{l}(\%)$ & $\begin{array}{l}\text { Lateral strain } \\
\text { ANN model }\end{array}$ & $\begin{array}{l}\text { Appropriate volu- } \\
\text { metric ratio ANN } \\
\text { model }\end{array}$ \\
\hline & 240 & 1500 & 6.3 & 70.00 & 660 & 0.8 & 0.529 & 60 & 0.0457 & Training & Training \\
\hline & 240 & 1500 & 6.3 & 60.00 & 660 & 0.93 & 0.529 & 124 & 0.053 & Training & Training \\
\hline & 240 & 1500 & 7.5 & 60.00 & 1000 & 1.32 & 0.703 & 124 & 0.0175 & Testing & Training \\
\hline & 240 & 1500 & 7.5 & 60.00 & 1000 & 1.32 & 0.703 & 92 & 0.0069 & Training & Training \\
\hline & 240 & 1500 & 7.5 & 100.00 & 1000 & 0.79 & 0.703 & 92 & 0.0445 & Training & Training \\
\hline & 240 & 1500 & 6.3 & 100.00 & 660 & 0.56 & 0.529 & 92 & 0.0208 & Testing & Training \\
\hline & 240 & 1500 & 11.3 & 135.00 & 400 & 1.35 & 0.423 & 92 & 0.0375 & Training & Training \\
\hline \multirow[t]{8}{*}{ Silva [30] } & 305 & 1600 & 11.3 & 100.00 & 440 & 1.40 & 0.21 & 35.5 & 0.0628 & Training & Training \\
\hline & 305 & 1600 & 9.5 & 100.00 & 560 & 1.00 & 0.25 & 35.5 & 0.0477 & Testing & Training \\
\hline & 305 & 1600 & 11.3 & 100.00 & 440 & 1.40 & 0.21 & 39.5 & 0.0512 & Training & Testing \\
\hline & 305 & 1600 & 9.5 & 100.00 & 560 & 1.00 & 0.25 & 39.5 & 0.0638 & Training & Training \\
\hline & 305 & 1600 & 11.3 & 75.00 & 440 & 1.86 & 0.21 & 59.6 & 0.0578 & Testing & Training \\
\hline & 305 & 1600 & 9.5 & 80.00 & 560 & 1.24 & 0.25 & 59.6 & 0.0273 & Training & Training \\
\hline & 305 & 1600 & 11.3 & 45.00 & 440 & 3.11 & 0.21 & 119.9 & 0.0442 & Training & Training \\
\hline & 305 & 1600 & 9.5 & 50.00 & 560 & 1.99 & 0.25 & 119.9 & 0.0568 & Training & Training \\
\hline
\end{tabular}

Table 2 The parameters of proposed ANN model

\begin{tabular}{ll}
\hline Parameters & $\begin{array}{l}\text { Lateral } \\
\text { Strain } \\
\text { Model }\end{array}$ \\
\hline Number of input layer nodes & 5 \\
Number of hidden layers & 1 \\
Number of hidden layer nodes & 15 \\
Number of output layer nodes & 1 \\
Momentum factor & 0.8 \\
Learning rate & 0.3 \\
Target error & 0.00001 \\
Learning cycle & 10,000 \\
\hline
\end{tabular}

\section{Appropriate volumetric ratio ranges of transverse reinforcements}

The appropriate volumetric ratio ranges of stirrups in different strength confined concrete were essential to design confined concrete. For a specific strength stirrups and a specific strength concrete, if the volumetric ratio of transverse reinforcements was low, concrete could not be confined effectively, on the contrary, if the volumetric ratio of transverse reinforcements was too high, it was hard for casting concrete and the strength of lateral steel could not be fully developed. Thus, it was critical to determine the appropriate volumetric ratio of spiral stirrups for designing

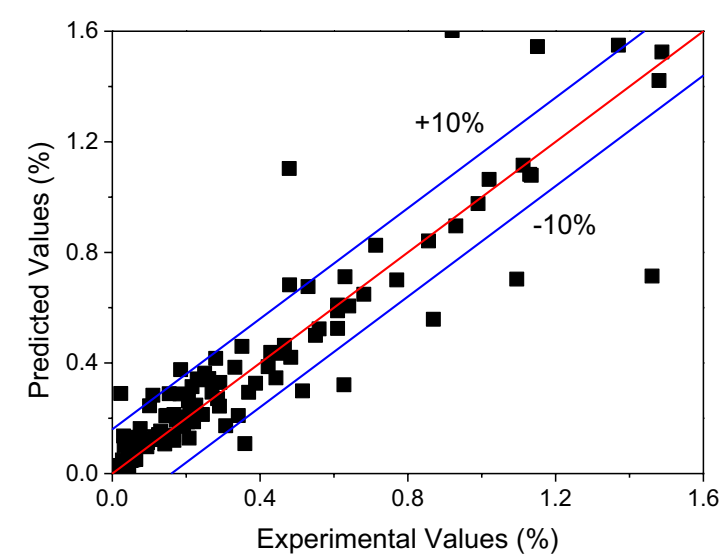

(b) ANN model$$
1
$$

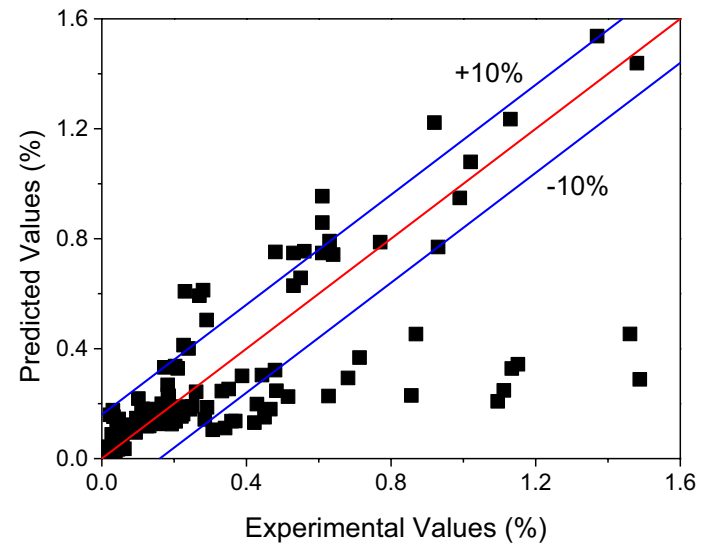

(a) Regression Analysis model

Fig. 5 Comparison between predict results from lateral strain prediction models and Experimental results from collected data. a Regression analysis model, $\mathbf{b}$ ANN model 
Table 3 Indicator values of proposed model

\begin{tabular}{lll}
\hline Indicators & Regression analysis model & ANN model \\
\hline RMSE & 1.1590 & 0.8542 \\
AAE & 0.6689 & 0.5077 \\
$R^{2}$ & 0.7840 & 0.9206 \\
\hline
\end{tabular}

confined concrete. In collected data sets, there were 45-group datasets represented that the stirrups yielded at the peak stress of confined concrete.

To establish the models for determining the appropriate volumetric ratio ranges of stirrups in different strength confined concrete, an ANN model was established. The authors defined that stirrups yielded at the peak stress was one, while stirrups did not yield was zero. As mentioned in Sect. 2, the ANN model for determining the appropriate volumetric ratio ranges of transverse reinforcements in different strength confined concrete was developed as follows:

- Select $80 \%$ (88 groups) of collected data sets to train the model and remaining data sets ( 23 groups) were applied to test the reliability of proposed ANN model;

- The inputs parameters included the compressive strength of unconfined concrete, the tensile strength and the voluimetric ratio of transverse reinforcemnets, the aspect ratio of specimens, as well as longitudinal reinforcements ratios, while the output values was one or zero representing the stirrups yield or not;

- The different strength lateral steel confined different strength concrete were tested the ANN model;

- Determine the appropriate volumetric ratio ranges of different strength concrete.

Table 4 lists the structure parameters of ANN model for determining the appropriate volumetric ratio ranges of

Table 4 Parameters in ANN models

\begin{tabular}{ll}
\hline Parameters & $\begin{array}{l}\text { Lateral } \\
\text { strain } \\
\text { model }\end{array}$ \\
\hline Number of input layer nodes & 5 \\
Number of hidden layers & 2 \\
Number of hidden layer 1 nodes & 12 \\
Number of hidden layer 2 nodes & 3 \\
Number of output layer nodes & 2 \\
Momentum factor & 0.8 \\
Learning rate & 0.01 \\
Target error & 0.00001 \\
Learning cycle & 50,000 \\
\hline
\end{tabular}

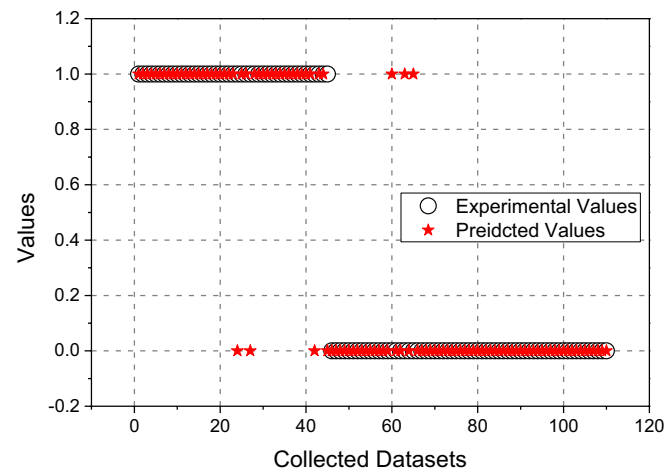

Fig. 6 Comparison between Experimental values and Predicted values from the proposed ANN model

transverse reinforcements in confined concrete and Fig. 6 shows the comparison between experimental values and predicted values from the proposed ANN model. In Fig. 6, 104-group datasets from the proposed ANN model of were equaled to experimental datasets, only 7-group datasets were different. Therefore, the proposed ANN model had high accuracy in determining whether stirrups yields at the peak stress of confined concrete.

Based on the proposed ANN model, the volumetric ratio of the different strength stirrups confined different strength concrete was determined to ensure that stirrups yield at the peak stress of confined concrete. To reach the purpose, the appropriate volumetric ratio ranges of stirrups confined concrete were evaluated by the proposed ANN model. Among test specimens, the tensile yield strength of transverse reinforcements included 300, 335, $400,500,600,800,970$, and $1270 \mathrm{MPa}$, the strength of concrete included $30,40,50,60,70,80,90$, and $100 \mathrm{MPa}$, the aspect ratio of specimens was 3 , and longitudinal reinforcements ratio was $0 \%$. The appropriate volumetric ratio ranges of different strength stirrups confined concrete are listed in Table 5. In Table 5, the volumetric ratio of stirrups in different strength stirrups confined a specific strength concrete could determine that stirrups yielded at the peak stress of confined concrete. The volumetric ratio ranges of transverse reinforcements increased with concrete strength. The minimum volumetric ratio of stirrups in low strength concrete was $0.8 \%$, but in high strength concrete was $0.6 \%$. Table 5 can provide a referee for the design of spiral stirrups confined concrete.

\section{Conclusion}

In this paper, the lateral performance of stirrups in confined concretes was evaluated. The lateral performance evaluation of stirrups included the prediction of the lateral 
Table 5 Appropriate Volumetric ratio ranges of stirrups in confined concrete

\begin{tabular}{|c|c|c|c|c|c|c|c|c|c|}
\hline \multirow[t]{2}{*}{$\rho_{\mathrm{sv}}(\%)$} & & \multicolumn{8}{|l|}{$f_{c} / \mathrm{MPa}$} \\
\hline & & 30 & 40 & 50 & 60 & 70 & 80 & 90 & 100 \\
\hline \multirow[t]{8}{*}{$f_{\mathrm{sv}}(\mathrm{MPa})$} & 300 & $0.9-2.0$ & $0.8-2.0$ & $0.8-2.0$ & $0.8-2.0$ & $0.6-2.0$ & $0.6-2.0$ & $0.6-2.0$ & $0.6-2.0$ \\
\hline & 335 & $1.0-2.3$ & $1.0-2.3$ & $1.0-2.3$ & $0.9-2.3$ & $0.9-2.3$ & $0.9-2.3$ & $0.9-2.3$ & $0.9-2.3$ \\
\hline & 400 & $1.2-2.8$ & $1.2-2.8$ & $1.2-2.9$ & $1.2-2.9$ & $1.1-2.9$ & $1.1-2.9$ & $1.1-2.9$ & $1.1-2.9$ \\
\hline & 500 & $1.5-3.7$ & $1.5-3.7$ & $1.5-3.7$ & $1.5-3.7$ & $1.5-3.7$ & $1.5-3.8$ & $1.5-3.8$ & $1.5-3.8$ \\
\hline & 600 & $1.8-4.5$ & $1.8-4.5$ & $1.8-4.6$ & $1.8-4.6$ & $1.8-4.6$ & $1.8-4.6$ & $1.8-4.6$ & $1.8-4.6$ \\
\hline & 800 & $2.5-6.2$ & $2.5-6.2$ & $2.5-6.3$ & $2.5-6.3$ & $2.5-6.3$ & $2.5-6.3$ & $2.5-6.3$ & $2.5-6.3$ \\
\hline & 970 & $3.2-7.7$ & $3.2-7.7$ & $3.1-7.7$ & $3.1-7.7$ & $3.0-7.7$ & $3.0-7.7$ & $3.0-7.8$ & $3.0-7.8$ \\
\hline & 1270 & $4.1-10.2$ & $4.1-10.2$ & $4.1-10.2$ & $4.1-10.2$ & $4.0-10.2$ & $4.0-10.3$ & $4.0-10.3$ & $4.0-10.3$ \\
\hline
\end{tabular}

strain and the determination of appropriate volumetric ratio ranges. To reach the purpose, the theoretical analysis on the lateral strain of stirrups in confined concrete was carried out to determine the effects of main influential parameters on lateral strain. Based on theoretical analysis and a reliable database consisting of 111-group data sets, a regression analysis model and an ANN model were established to predict lateral strain of stirrups at the peak strain of confined concrete. Besides, an ANN model for determining the appropriate volumetric ratio of confined concrete was established to instruct the design of spiral stirrups confined concrete. The conclusions were drawn as follows:

(1) The effects of main influential parameters of the lateral strain of transverse reinforcements included the aspect ratio of specimens, the volumetric ratio and the tensile strength of transverse reinforcements, the ratio of longitudinal reinforcements, as well as the compressive strength of concrete on the lateral strain of stirrups in confined concrete were determined by analyzed;

(2) A regression analysis model was established based on theoretical analysis and an ANN model was established to predict the lateral strain of confined concrete. Both those proposed two models high accuracy for predicting the lateral strain of confined concrete. Besides, the predicted values from the ANN model were more accurate and more reliable than the regression analysis model, while the formula of regression analysis model was more specific than ANN model;

(3) The ANN model was established to determine the volumetric ratio ranges of transverse reinforcements to ensure that transverse reinforcements yield at the peak stress of confined concrete. This model had a high significance in predicting the peak strain and the peak stress of confined concrete in existing analytical models, meanwhile, the appropriate volumetric ratio ranges of transverse reinforcements can provide a referee for the design of spiral stirrups confined concrete.

(4) The ANN model was first applied to evaluate the lateral strain of stirrups in confined concrete. Determining the appropriate volumetric ratio ranges of stirrups in confined concrete was important to judge stirrups yield at the peak stress of confined concrete.

\section{Compliance with ethical standards}

Conflicts of interest The authors declare that they have no conflict of interest.

\section{References}

1. Li B, Park R (2004) Confining reinforcement for high-strength concrete columns. ACI Struct J 101(3):314-324

2. Saatcioglu M, Razvi SR (1998) High strength concrete columns with square sections under concentric compression. J Struct Eng 124(12):1438-1447

3. Razvi SWN, Shaikh MG (2018) Effect of confinement on behavior of short concrete column. Procedia Manuf 20:563-570

4. Micell F, Mazzotta R, Leone M, Aiello MA (2015) Review study on the durability of FRP-confined concrete. J Compos Constr 19(3):04014056

5. Mander JB, Priestley MJN, Park R (1988) Theoretical stress-strain model for confined concrete. J Struct Eng 114(8):1804-1826

6. Richart FE, Brandtzæg A, Brown RL (1928) A study of the failure of concrete under combined compressive stresses. Univ Illinois Eng Exp Stn Bull 185:1-102

7. Richart FE, Brandtzæg A, Brown RL (1929) Failure of plain and spirally reinforced concrete in compression. Univ Illiois Eng Exp Stn Bull 190:1-71

8. Saatcioglu M, Razvi SR (1999) Circular high-strength concrete columns under concentric compression. ACI Struct J 96(5):1438-1447

9. Légeron F, Paultre P (2003) Uniaxial confinement model for normal- and high-strength concrete columns. J Struct Eng 129(2):241-252

10. Nakazawa N, Kawashima K, Watanabe G, Sakai J (2014) A confinement model of high strength concrete, 13th world 
conference on earthquake engineering, Vancover, Canada, vol 873, pp 873-886

11. ACl Committee (2012) 318, Building code requirements for structural concrete, $\mathrm{ACl} 318$. American Concrete Institute, Farmington Hills

12. Zheng WZ, Hou CC (2016) Design method for confined concrete column with different yield strength stirrups. J Build Struct 37(12):74-82

13. Dong CX, Kwan AKH, Ho JCM (2015) A constitutive model for predicting the lateral strain of confined concrete. Eng Struct 91:155-166

14. Kwan AKH, Dong CX, Ho JCM (2016) Axial and lateral stressstrain model for circular concrete-filled steel tubes with external steel confinement. Eng Struct 117:528-541

15. Kim YS, Kim HG, Park CB, Kim SW, Kim KH (2017) Evaluation of minimum spiral reinforcement ratio of circular RC columns. J Korea Inst Struct Maint Insp 21(6):001-009

16. Alacali SN, Akbas B, Doran B (2011) Prediction of lateral confinement coefficient in reinforced concrete columns using neural network simulation. Appl Soft Comput 11:2645-2655

17. David AF (2005) Statistical models: theory and practice. Cambridge University Press, Cambridge

18. Fisher RA (1922) The goodness of fit of regression formula, and the distribution of regression coefficients. J R Stati Soc 85(4):597-612

19. Fotheringham AS, Wong DWS (1991) The modifiable areal unit problem in multivariate statistical analysis. Environ Plan A 23(7):1025-1044

20. Tofallis C (2009) Least squares percentage regression. J Mod Appl Stat Methods 7:526-534

21. Tanaka T, Kawakami W, Kuwabara S et al (2019) Intelligent monitoring of optical fiber bend using artificial neural networks trained with constellation data. IEEE Netw Lett 1(2):60-62

22. Palanivel R, Dinaharan I, Laubscher RF (2019) Application of an artificial neural network model to predict the ultimate tensile strength of friction-welded titanium tubes. J Brazil Soc Mech Sci Eng 41(2):111

23. Alshihri MM, Azmy AM, El-Bisy MS (2009) Neural networks for predicting compressive strength of structural light weight concrete. Constr Build Mater 23(6):2214-2219

24. Mander JB, Priestley MJN, Park R (1988) Observed stress-strain behavior of confined concrete. J Struct Eng 114(8):1827-1849

25. Antonius A (2000) Performance of high-strength concrete columns confined by medium strength of spirals and hoops. Asian J Civil Eng 46(3):757-766

26. Assa B, Nishiyama M, Watanabe F (2001) New approach for modeling confined concrete II: rectangular columns. J Struct Eng 127(7):751-757

27. Li B (1993) Strength and ductility of reinforced concrete members and frames constructed using high strength concrete. Civil Engineering at the University of Canterbury, Christchurch

28. Montgomery DL (1996) Behavior of spirally reinforced high strength concrete columns under axial loading. Thesis for the Degree of Master of Applied Science Graduate Department of Civil Engineering, University of Toronto

29. Razvi SR, Saatcioglu M (1996) Test of high-strength concrete columns under concentric loading. Rep. No. Oceerc 96-03, Ottawa Carleton Earthquake Engineering Research Centre, Ottawa, ON, Canada

30. Silva PD (2000) Effect of concrete strength on axial load response of circular columns. McGill University, Canada

Publisher's Note Springer Nature remains neutral with regard to jurisdictional claims in published maps and institutional affiliations. 